\title{
Implementing the Right to Treatment
}

\author{
David L. Bazelon†
}

Any court decision which even smacks of novelty can be counted upon to spawn a rash of commentary. The floodgates predictably opened before the ink had dried on Rouse v. Cameron. ${ }^{1}$ As its author, I have read the articles, student notes, and symposia devoted to Rouse with only an occasional wince of pain or howl of outrage.

The controversy over Rouse has focused not on the validity of the right to treatment, but on the competence of courts to protect that right. Pundits both legal and medical were swift to point out that adequate treatment is a quicksilver concept. Different psychiatrists have radically different ideas of what constitutes good treatment either in general or for a specific patient. Judges have little basis to choose among the varieties of treatment, and certainly cannot formulate for themselves standards for adequate treatment.

These observations, unquestionably true enough, led many critics toward the conclusion that courts should leave doctoring to the doctors. The American Psychiatric Association took this position forthrightly with an official policy statement in direct response to Rouse: "The definition of treatment and the appraisal of its adequacy are matters for medical determination." 2 Legal commentators were more circumspect, but their doubts concerning the judicial enforceability of a right to treatment were evident. The editors of the Harvard Law Review solemnly admonished me, "The difficulty of formulating

† Chief Judge, United States Court of Appeals, District of Columbia Circuit. This address was delivered by Judge Bazelon at a Wayne State University Law School Symposium on The Mentally Ill and the Right to Treatment, April 18, 1969.

1373 F.2d 451 (D.C. Cir. 1966). Rouse, after his acquittal by reason of insanity on a charge of carrying a dangerous weapon (a misdemeanor punishable by a maximum sentence of one year), was involuntarily committed to Saint Elizabeths Hospital as required by law. D.C. CODE ANN. § 24-301(d) (1967). Rouse brought a habeas corpus action alleging, inter alia, that he was not receiving treatment. The Court of Appeals for the District of Columbia Circuit, reversing the district court, held that the right to treatment established by statute, D.C. ConE ANN. $\S 21-562$ (1967), is a right guaranteed to those involuntarily committed by reason of insanity; and that unless plaintiff receives such treatment, his detention violates the law of the United States and he is entitled to relief on habeas corpus.

2 Council of the American Psychiatric Association, Position Statement on the Question of Adequacy of Treatment, 123 AMr. J. Psychiatry 1458 (1967). 
standards of adequacy seems very great." 3 The future lawyers at Yale, in their occasionally published Law Journal, fretted at length about "the difficult problems courts will face in administering a right to treatment." ${ }^{\prime 4}$ If psychiatric standards for adequate treatment are uncertain among experts and incomprehensible to mere judges, then perhaps we must admit, however reluctantly, that Rouse discovered the fabled right without a remedy.

But such diffidence in the face of scientific expertise is conduct unbecoming a court. Very few judges are psychiatrists. But equally few are economists, aeronautical engineers, atomic scientists, or marine biologists. For some reason, however, many people seem to accept judicial scrutiny of, say, the effect of a proposed dam on fish life, while they reject similar scrutiny of the effect of psychiatric treatment on human lives. Since it can hardly be that we are more concerned for the salmon than the schizophrenic, I suspect the explanation must lie in our familiarity with judicial supervision of such matters as railroad rates, airplane design, power plant construction, and dam-building. While the importance of this factor can be overestimated, in the law as in all other areas we tend to accept the accustomed and fear the new.

The Cassandras that foresee judges wallowing hopelessly in the bogs of psychiatry seldom distinguish the problems of enforcing a right to treatment from those encountered whenever courts deal with complicated questions of science and technology. But such distinctions are essential to any argument that standards for treatment are so lacking and judicial ignorance so great that constructive court intervention is impossible. For the obvious rejoinder to this criticism of Rouse is to invoke the administrative model.

Ever since Congress created the Interstate Commerce Commission in 1887, judges have enforced complex statutory schemes. In many areas the experts have been in conflict, and in almost all cases judges have been uniformly ignorant. No one would extol the administrative law. Courts still search for standards in many areas, and experts still pounce upon decisions exemplifying judicial misunderstanding of, for example, the basic tenets of price theory.

But experience has taught us to minimize these disasters. The administrative law has not reached the millenium, but as we approach the century mark, the outlines of effective administrative action and judicial review are visible. Properly qualified experts at the adminis-

380 HARv. L. REv. 898, 900 (1967).

4 Note, Civil Restraint, Mental Illness, and the Right to Treatment, 77 YALE L.J. 87, 91 (1967). 
trative level can tackle the most complex technical problems in a variety of ways, from rule-making procedures to formal adjudicatory hearings. Reviewing courts can in turn scrutinize administrative determinations while avoiding the rock and the whirlpool of rubberstamping or unwisely ignoring the judgments of experts.

Semantic quibbles over the proper phrasing of the "substantial evidence" test will persist as long as lawyers love logomachies. But the core concept is easily articulated. When administrators have conscientiously applied their expertise to a problem demanding technical knowledge and experience, judges will not substitute their own uninformed judgment. The duty of the reviewing court is rather to study the record, including most importantly the findings and conclusion of the commission involved, to insure that the administrators have performed their task with care and reached a reasonable result.

Of course, the scope of judicial review varies somewhat according to the nature of the administrative proceeding. Detailed findings and conclusions are not demanded for informal rule-making; a concise statement of the "basis and purpose" of the rules is sufficient to inform the reviewing court what major issues of policy were ventilated by the informal proceedings and why the agency reacted to them as it did. At other times, such as when a constitutional right is directly involved, the court does not defer to the administrative agency: the expertise in that situation belongs to the judge.

It is often unclear precisely what scope of review is appropriate, or what result such review demands. But the principle of a division of responsibility between administrators skilled in their area and judges skilled in the law is clear and has proved workable. For those who lament the lack of standards which dooms the right to treatment, the obvious challenge is why our experience in administrative law is inapplicable to this field.

Psychiatrists' disagreements about treatment, while admittedly of epic proportions, do not seem qualitatively different from those among experts in other fields. The American Journal of Psychiatry, after all, along with other professional journals, appears monthly with learned articles on treatment for the mentally ill. Surely the editors of that august publication do not find the varieties of treatment so infinite in number and indistinguishable in quality that they are unable to select among submitted manuscripts.

Nor do judges seem necessarily more ignorant and uneducable in psychiatry than in other fields. The more relevant question is whether judges can hope to learn enough within the narrow compass 
of cases brought before them to reach constructive decisions. When the limited function of a judge in reviewing administrative determinations is borne in mind, there seems little to distinguish psychiatry from, say, radio broadcasting. No judge would claim the ability to prescribe a particular therapy for a "chronic undifferentiated schizophrenic." But neither would any judge allocate AM frequencies to avoid interference. That is not his task in either case; his role rather is to determine whether a capable expert has studied the problem fully and reached a defensible result. To focus more closely upon the right to treatment, the judge must decide only whether the patient is receiving carefully chosen therapy which respectable professional opinion regards as within the range of appropriate treatment alternatives, not whether the patient is receiving the best of all possible treatment in the best of all possible mental hospitals.

Perhaps I have been flaying the famous dead horse, however. The chief difficulty with applying principles of administrative law in the right-to-treatment area may not be that the problems involved are intrinsically more difficult than those in fields where the administrative model has proved a tolerable success, but that we simply lack the administrative machinery and legislative standards necessary to apply that model here.

This is a more limited argument, of course. It leads not to the conclusion that the right to treatment is intrinsically unwise or unenforceable, but only to the proposition that courts cannot implement the right without the aid of a legislative framework. Moreover, to the extent that the legislature commits the community to providing treatment for patients involuntarily hospitalized for that purpose, precisely the same considerations suggest that the legislature may also commit itself to provide the standards and machinery necessary to assure the reality of treatment.

There is no question but that a legislature could, if it wished, do much to protect the right to treatment. Since I am no more a legislator than a psychiatrist, I cannot presume to spell out the standards a legislature might establish for adequate treatment. In many ways legislators have greater resources than judges for broad fact-finding and policy-planning proceedings. But a few speculations may be useful in considering what legislation might accomplish.

The concept of treatment must function at two levels. The first might be termed, prosaically, treatment in general: the degree to which a mental hospital possesses the staff and resources to provide help to all its patients. A recent bill ${ }^{5}$ proposed in the Pennsylvania

5 S.B. 1274 \& H.B. 2118, Pa. Gen. Assembly, 1968 Sess. 
legislature thus provided for a Mental Treatment Standards Committee that would have compiled a manual of minimum treatment standards covering such matters as the number of professional and non-professional staff; the minimum number of consultations and the number of hours of individual consultations to be provided each patient over a given period; and the frequency of physical examinations.

An adumbration of such general standards for treatment is valuable. A hospital obviously cannot provide adequate treatment for a given patient if it provides no treatment for any patient. But the mere fact that a hospital can provide some treatment for all patients should not, as some courts have been content to conclude, satisfy the requirement of adequate treatment for the individual patient. The most important facet of the right to treatment is not that the hospital does something for everyone, but that it does the right thing for the right patient. Because individual patients, particularly mental patients, vary so much in their needs, considerable attention must be paid to the patient as an individual.

Any legislative definition of adequate treatment should therefore insure not only that the hospital provides treatment in general, but also that it tailors the treatment offered to the specific patient. One possible beginning would be the sort of standards set up by the Social Security Administration in defining "active treatment" for the purpose of reimbursing hospitals for services rendered Medicare patients. ${ }^{6}$ The Administration guidelines provide, in summary: for services in a psychiatric hospital to be designated as "active treatment," they must be (a) provided under an individualized treatment or diagnostic plan, (b) reasonably expected to improve the patient's condition or for the purpose of diagnosis, and (c) supervised and evaluated by a physician.

The need for an individualized treatment plan cannot be overemphasized. Without such a plan, there can be no evidence that the hospital has singled out the patient for treatment as an individual with his own unique problems. And unless the plan is refined and improved on the basis of experience, there can be no guarantee that the promise of treatment has taken root in reality.

However desirable clearly articulated legislative standards may be, though, any realist must admit that the demand for such standards in the administrative law has persistently exceeded the supply. When the goals of a regulatory program are unexplained, there is no doubt but that nebulous statutes directing an agency "to promote the pub-

620 C.F.R. $\S \S 405.1036-8$ (1969). 
lic interest" typically promote only administrative chaos. But relatively few statutes creating new regulatory programs have traveled beyond vague yearnings and dimly perceived ideals to provide detailed roadmaps to salvation. Even when the mischief is thoroughly understood, the precise remedy is often of necessity left to the new agency for discovery. Appropriate and workable standards are developed through a process that traces a spiral from legislature to agency to court and back to legislature. The agency fleshes out by regulations the legislative standards. After courts have attempted to review the application of the regulations to concrete cases, the legislatures may perhaps draw upon their experiences to provide a better, more definitive solution.

Everyone should agree that legislation to define adequate treatment would be a godsend. There will likely be less consensus whether our present understanding of the contours of treatment falls fatally short of the "standards" that could reasonably be expected of a legislature. Whatever our conclusions on that score, however, the success of many regulatory schemes blessed with less than luminous legislative standards teaches us that the machinery created to carry out an administrative program is at least as important as detailed legislative guidance.

If a legislature were so inclined, it could provide the sort of policymaking and enforcement machinery characteristic of administrative agencies in order to protect the right to treatment. The unsuccessful bill in Pennsylvania ${ }^{7}$ to which I alluded earlier ${ }^{8}$ would have partially done this. In addition to the Mental Treatment Standards Committee, it would have created a Patient Treatment Review Board to examine patients' claims that they were receiving inadequate treatment. The best hope for the right to treatment would be legislation of this sort. Even if adequate standards for treatment were initially absent, a statute creating a commission, agency or whatever capable of (1) formulating standards for treatment and (2) enforcing or at least adjudicating the rights of patients would thrust the nascent right to treatment toward the mainstream of the administrative process.

Today there is no such legislation, however, and so the question must be whether present institutions can perform the functions required if analogies to the administrative law are to be more than whimsical. The fundamental problem is that until legislatures consider the problem, the hospital administration must be all things. The hospital must both provide treatment and review its adequacy. In

7 S.B. 1274 \& H.B. 2118, Pa. Gen. Assembly, 1968 Sess.

8 See text at note 5 supra. 
discussing the possible form legislative standards for treatment might take, I have adverted to the fundamental necessity for individualized treatment plans and records in the administration of treatment. Some mechanism for internal review is equally essential. Rouse v. Cameron suggested that Saint Elizabeths Hospital might establish procedures to review patients' claims of inadequate treatment. ${ }^{9}$ To the best of my knowledge, no such procedures have been created. But there seem no insurmountable obstacles to such a step.

Because any such reviewing function would need to take place within the hospital, certain precautionary steps would be necessary to provide for some separation of functions. For example, any reviewing body should certainly be independent from the psychiatrist or psychiatrists responsible for treating the patient involved.

If such steps were taken, many of the teeth could be drawn from the most popular criticisms of the right to treatment even without legislation. Doctors, not judges, could formulate standards for adequate treatment. And experts qualified to appraise treatment could make at least the initial determination whether a particular patient was receiving treatment. The courts could limit their role to that played in reviewing administrative decisions-a scrutiny of the record to determine whether the professionals providing and evaluating treatment have made responsible decisions based upon a thorough consideration of all the evidence relevant to the individual case.

The rationale for the right to treatment is clear. If society confines a man for the benevolent purpose of helping him-"for his own good," in the standard phrase-then its right to so withhold his freedom depends entirely upon whether help is in fact provided. It may be that the person is not treatable or that the treatment effort is too costly in light of the chances of success. If this is the view of the professional, it should be spread clearly upon the record so that we do not delude ourselves by calling these unfortunates "patients." But whenever care is simply custodial, we must be certain beyond a reasonable doubt-and I import this legal phrase deliberately-that the individual truly could not hope to care for himself. And when the rationale for institutionalization is not that the person would be dangerous to himself, but that he would be dangerous to others, we must be even more careful. Whatever justification we may find in theories of retribution or general deterrence for confining a convicted criminal, the case is quite different when the individual has committed no crime. Confinement in this situation is, to employ an emotive but accurate term, preventive detention. As such, it is 
appropriate, if ever, only when the probability of future harmful conduct is high indeed. And when prediction is impossible, we cannot ask the individual to suffer from our uncertainty.

Moreover, needless to say, preventive detention demands standards of procedural due process at least as high as in the criminal law. No civil commitment law begins to meet those substantive and procedural standards, either in language or in operation. The statutes themselves too often speak with archaic and infuriating imprecision. And in operation, the agency or court responsible for commitments typically contents itself with vague statements from a psychiatrist who has conducted a cursory examination that the individual "could be" dangerous or "might be" dangerous. The awesome uncertainty about dangerousness reflected in such language is tolerated on the rationalization that the person is not being imprisoned, but rather hospitalized for treatment. Of course, when no treatment is forthcoming, we cluck sympathetically but reluctantly refuse to release the individual because he is dangerous.

This chicanery is intolerable. Courts cannot force legislatures to provide adequate resources for treatment. But neither should they play handmaiden to the social hypocrisy which rationalizes confinement by a false promise of treatment. Quite the contrary, courts should and must reveal to society the reality that often festers behind the euphemism of "hospitalization." Some might call this judicial muckraking. But courts fulfill a necessary function when the drama and publicity attending a concrete case provide the illumination of dark recesses which is essential if society and its legislatures are to make informed judgments.

If this is true, judges may in fact hope to have some effect on the availability of resources by exposing the inadequacy of treatment in many of today's public hospitals, and thereby allowing the community to make an honest choice to honor its promises or to withdraw them.

More important, by this analysis the inadequacy of resources emerges as anything but a justification for a failure to provide treatment. When the legislature justifies confinement by a promise of treatment, it thereby commits the community to provide the resources necessary to fulfill the promise. In the rarefied world of orthodox legal reasoning, infinitely more elegant statutory and constitutional arguments are possible and perhaps necessary. But whether the right to treatment is rooted in statutory provisions or in concepts of due process of law, equal protection, or cruel and unusual punishment, the duty that society assumes, to fulfill the promise of treatment employed to justify involuntary hospitalization, is clear. 
From the preceding analysis three propositions emerge: (1) standards for adequate treatment are sorely lacking within the psychiatric profession, and judges are ill-equipped to resolve such disputes; (2) experience with the administrative process suggests that courts could cope with these far-from-unique problems if legislatures created the necessary machinery to define, administer, and evaluate treatment; (3) a reasonable though more debatable argument can be made that courts and hospital administrators could profitably apply principles of administrative law to implement the right to treatment even in the absence of legislation.

The conclusion or perhaps more accurately the reasonable expectation that the right to treatment can prove workable does not imply that enforcement of the right will prove frictionless. Nor, more importantly, does it imply that even the most perfect realization of the right would eliminate the need for thorough reexamination of our practices relating to mental illness. The right to treatment announced in Rouse and analyzed in this essay may someday prove to have been only a stopgap solution to an unnecessary problem. Before examining this possibility, however, the reasons deserve scrutiny why the right to treatment can be at best but a semi-solution to the problems created by involuntary hospitalization.

The District of Columbia, unlike many jurisdictions, has a rich lode of appellate decisions dealing with mentally ill persons. The majority of these cases have arisen out of criminal trials where defendants advanced the insanity defense. The prolixity of case law in that area arises partially from the Durham ${ }^{10}$ decision in 1954, which attempted to broaden the psychological inquiry by which criminal responsibility is determined. Administration of the Durham rule ${ }^{11}$ has revealed several difficulties, chief among which has been the adequacy of psychiatric testimony and the quality of the legal representation available for indigent defendants. Expert witnesses have often wished to testify in conclusory terms; lawyers have too often allowed them to.

Both the medical and the legal professions must bear part of the responsibility for the inadequate trials that have sometimes resulted. Doctors too often fail to understand the purpose of the insanity defense, and the role assigned to them. In other cases they have perhaps understood their proper role, but have been reluctant to play it. Attorneys appointed to represent indigent clients have frequently

10 Durham v. United States, 214 F.2d 862 (D.C. Cir. 1954).

11 " $[\mathrm{A}] \mathrm{n}$ accused is not criminally responsible if his unlawful act was the product of mental disease or mental defect." 214 F.2d at 874-5. 
proved unprepared to deal with conceptual and evidentiary problems incident to an insanity defense. Unlike many other areas of the law where affluent clients queue up to purchase representation, no specialized bar has developed with experience and expertise in the problems of the mentally ill. Consequently, the typical attorney appointed to represent a defendant who may be mentally ill has rarely if ever encountered the insanity defense before.

These problems are multiplied when the right to treatment rather than the insanity defense is involved. An insanity defense represents merely one facet of a criminal trial that would occur in any event. Almost all defendants at least have an attorney. An assertion that treatment is inadequate arises in an entirely different context. The patient is already hospitalized. He normally has no lawyer. Except for the fuss he created by claiming a right to treatment, there would be no court proceeding.

As a result, many patients are unaware of any right to treatment. Those that are rarely can afford a lawyer or represent themselves. One recent case in the District of Columbia, for example, involved a 57year-old civilly-committed indigent with a tested I.Q. of $52 .{ }^{12}$ To expect this man to file a petition for a writ of habeas corpus that even states his claims understandably, let alone approaches the requirements of common law pleading, is absurd. Luckily, his petition did raise certain issues requiring a hearing, however inartfully, and an attorney was appointed. The lawyer specialized in proceedings before the Interstate Commerce Commission. While he was undoubtedly wellqualified in his appearances before that forum, the record in Covington $v$. Harris ${ }^{13}$ suggests he was a neophyte in the area of mental illness. As such, the attorney made the mistakes beginners always do, missing some issues and failing to develop others either through independent evidence or penetrating cross-examination of the hospital's witnesses.

As a result, 24 months after James Covington filed his original petition, and after two hearings in the district court, the Court of Appeals was forced to remand the case for still further proceedings. ${ }^{14}$ Yet while the untutored observer would hardly so conclude, Covington represents a success story by the standards of right-to-treatment litigation. He got into court. Eventually, on appeal, he was fortunate to receive superb legal representation by two of the few lawyers with experience in the field. While his lawsuit has yet to bear fruit, someday, after the remand hearing and gracious knows what further pro-

12 Covington v. Harris, No. 21,935 (D.C. Cir., March 14, 1969).

13 Id.

14 Id. 
ceedings, he may obtain at least a transfer to a less restrictive hospital ward than the maximum security John Howard Pavilion at Saint Elizabeths Hospital.

The Covington case illustrates another difficulty with the right-totreatment approach. At the time of his petition, Mr. Covington had been languishing in the John Howard Pavilion for ten years. Whatever the quality of the treatment he received before beginning his lawsuit, it improved markedly when the hospital confronted the prospect of court scrutiny. The improvement indeed was so dramatic that his appellate counsel abandoned the treatment issue and focused instead upon the conditions of his confinement. This also represented success for Mr. Covington: he achieved better treatment without the need for a court order. But one cannot help speculating whether his success will spill over to other patients who have not yet petitioned for habeas corpus. Because of the natural desire of hospital administrators to avoid appearing in court to contest the claims of patients receiving no treatment, there is perhaps a danger that treatment efforts will be concentrated upon patients who initiate lawsuits-which may actually, because resources are so scarce, result in less treatment for less litigious patients. How accurately this may describe the actual dynamics of treatment I could not pretend to say. But the possibility is not attractive.

Many of these difficulties could be minimized, of course, by the creation of suitable devices to assure better representation for patients in initiating and pursuing claims for treatment. But these problems are inevitable as long as the right to treatment must be enforced on a case-by-case basis. As long as we have patients deprived of their liberty by the promise of treatment, such enforcement is necessary. Its inconveniences must be minimized, of course, but to the extent they cannot be eliminated without emasculating the right, both lawyers and doctors must devote time and effort to supervising society's fulfillment of the involuntary bargain thrust upon the individual who must exchange his right to liberty for a right to treatment. This fact suggests still another reason for reexamining the practice of involuntary commitments.

The judicial need for a right to treatment arises primarily because we have hundreds of thousands of patients residing-voluntarily or not-in state institutions. In the vast majority of cases, even if we resist the temptation to call these unfortunates "prisoners," it is fairer by far to refer to them as "residents" than as "patients." Rare is the person with a physical ailment who remains a hospital patient for years on end. While an equation between mental and physical 
illness is simplistic, any layman must view with skepticism the description as "patients" of persons who remain for years in our isolated, often overcrowded public mental institutions. The fact that such skepticism took so long to surface testifies to the capacity we all share to mask harsh realities with gentle words.

The public tolerance for euphemism may finally have exhausted itself in this area. There are powerful currents at work upon the entire structure of society's response to the mentally ill. Some of our concern is moral: do we have the right to lock the sick person away for years or decades? Other concerns are therapeutic: even if money were available for long-term treatment, could we treat an illness that arose in a particular family and community - to which the patient we hope will someday return-in isolation from these forces? And, inevitably, the availability of resources must also be among our concerns: can we or will we provide the sort of treatment necessary to resolve fundamental personality problems for the troubled hordes who might benefit from extended therapy?

The right to treatment does nothing to resolve these questions. It can function to enforce what may be loosely termed the bargain between society and the involuntarily hospitalized patient; it does not reexamine whether the bargain imposed is wise or even justifiable. If we promise treatment in exchange for liberty, courts must force the community to hew to the bargain. But is the bargain fair or necessary?

California has recently enacted legislation which promises virtually to eliminate involuntary hospitalization except for short-term crisis situations. ${ }^{15}$ A thorough examination of the Lanterman-Petris-Short Act would carry us far afield. The new statute carefully avoids the slovenliness of language which has scuttled other well-intentioned legislation. The procedural protections it promises are impressive indeed when compared with commitment proceedings in other states. A thoroughly jaded eye could, of course, find room for unnatural play in the joints of the new act. Only experience will reveal whether California can truly end involuntary commitments as a principal response to mental illness, and avoid the potential sequelae of voluntary commitments which are the product of subtle coercion.

But the careful drafting of the Lanterman-Petris-Short Act allows us all to hope. If its goals are achieved, the necessity for a right to treatment in its present form will wither away. If this happens, and I hope it will, the path will be cleared for society to confront the right to treatment in its more fundamental form. We should ultimately

15 Lanterman-Petris-Short Act, CAL. WELF. \& INST. CODE $\$ 5000$ et seq. (Deering Supp. 1968). 
ground the right to treatment not in our duty to help the mentally ill person as a quid pro quo for confining him, but in our duty to help him as a troubled human being in our midst. As a human being, I have no doubt of the existence of this duty. As a judge, it would be wholly inappropriate for me to predict the ways in which this more basic right to treatment may take root in the law. Certainly the law approaches more closely every day the realization that individuals have definite entitlements that they may claim rather than request. We no longer regard the welfare client as a supplicant who must accept our bounty with whatever degrading conditions we choose to attach. We may soon realize that the necessities of life are a matter of personal right and societal duty, and not a bounty at all. Mental health is the most basic of these necessities. We owe it to every man. 